\title{
Effect of Smoke Exposure on Chronic Inflammation and P53 Expression in Bladder Epithelial
}

\author{
Nur Budaya T, Surya Putra T, Daryanto Besut, Anita Kenty W
}

\begin{abstract}
Bladder cancer is widely studied for its association with cigarette smoke (CS) exposure. Nicotine and carcinogenic substances in CS could induce chronic inflammatory state and DNA damage. This research was aimed to investigate the effect of CS exposure in chronic inflammatory state and p53 expression in bladder epithelial of Wistar rats. 25 male Wistar rats aged 6-8 weeks were divided into five groups as follows: Control (without treatment); CS-1, CS-2, CS-4, and CS-8 (treated with CS $1 x, 2 x, 4 x$, and $8 x /$ day, respectively). Each exposure was done for 15 minutes for 60 days. Chronic inflammatory score was calculated from HE-stained specimens and Immunohistochemistry method was applied to measure p53 expression. Results showed that lymphocyte and histiocyte count in CS-8 was significantly higher as compared to CS-1 (p<0.05) and control $(p<0.05)$. Lymphocyte and histiocyte count in CS-4 was also significantly higher compared to non-treated group $(p<0.05)$. Chronic inflammatory score was significantly higher in CS-8 compared to other group $(p<0.05)$. Moreover, p53 expression was found in CS-8 group (2 of 5 subjects had positive p53 expression, 20 positive cells in from total 10 hpf) and significantly different with other groups $(p=0.011)$. Correlation study showed significant correlation between frequency of cigarette smoking exposure and lymphocyte count $(p=0.000$; $r=0.956) ;$ monocyte count $(p=0.000 ; \quad r=0.928) ; \quad$ chronic inflammation score $(p=0.000 ; r=0.928) ;$ and $p 53$ expression $(p=0.007 ; r=0.522)$. We concluded that there was significant differences in chronic inflammation state and p53 expression among groups. Correlation study showed that frequency of cigarette smoking exposure was positively correlated with chronic inflammation and 53 expression.
\end{abstract}

Keywords: bladder, chronic inflammation, cigarette smoke, p53.

\section{INTRODUCTION}

Epidemiological study reported that the bladder cancer incidence was 429.793 with 165.084 mortality rate in 2012.1 Bladder cancer is common in elderly patient, it has median of age 72 years old but rarely observed in patient $<40$ y.o. 2 Bladder cancer is more frequent in men the in women, prevalence in women was increase $0.2 \%$ year. 3 Transitional bladder cell carcinoma (SCC) type is the most common in Developed country, 2 while in developing countries, squamous cell carcinoma (SCC) type is more frequent.4,5

Revised Manuscript Received on January 2, 2020.

* Correspondence Author

Nur Budaya T*, Department of Urology, Faculty of Medicine, Universitas Brawijaya, Malang, Indonesia, Email: taufiq_fkub03@yahoo.com

Surya Putra T. Department of Urology, Faculty of Medicine, Universitas Brawijaya, Malang, Indonesia

Daryanto Besut, Department of Urology, Faculty of Medicine, Universitas Brawijaya, Malang, Indonesia

Anita Kenti W, Department of Pathology Anatomy, Faculty of Medicine, Universitas Brawijaya, Malang, Indonesia

The accurate incidence of bladder cancer in Indonesia has not known yet. However, data from GLOBOCAN predicted that bladder cancer was accounted for 5,8 per 100.000 populations.6 Data from Saiful Anwar Hospital within interval 2012-2018 reported 287 cases of bladder cancer.

Cigarette smoking has been widely studied for its correlation with the development of bladder cancer.7-9 Aromatic amine consisting in cigarette smoke will be metabolized into highly carcinogenic form, N-hydroxylamine.10 Genetic polymorphism regarding enzymatic capacity to neutralize this substance was associated with bladder cancer risk.11 Evidence showed that heavy smoker has higher risk for bladder cancer compared with light smoker. Consistently, smoking cessation has beneficial effect on reducing the risk. Beside the intensity of smoking, the duration of smoking12-14 and type of tobacco8 also contribute to bladder cancer risk.

Beside the direct carcinogenic or mutagenic effect, oxidant-containing cigarette smoke could trigger oxidative stress and chronic inflammatory state. Nicotine could induce the production of hydrogen peroxide and anion superoxide which could further disrupts mitochondrial function.15 For a long term period, oxidative stress and chronic inflammatory state impair the cellular regulation on apoptosis, thus cause tissue damage and remodeling.16 Furthermore, chronic inflammatory state which is characterized by macrophage infiltration had been studied for its role in the cellular transformation into malignancy.17,18

Protein p53 is a transcriptional factor and essential in regulation, apoptosis, and DNA restoration. Lack of functional p53 was correlated with chemotherapy resistance.19 Previous studies reported that intravenous administration of nicotine reduced the p53 expression in lung, liver, kidney, and bladder.20 At certain point, nicotine or other substances in cigarette smoke possibly cause DNA damage, including p53 gene.21 Damaged DNA could be a potential risk for gene mutation, including p53. Observational studies reported that mutation of p53 was highly found in high grade bladder cancer22 and associated with the incidence of TCC in uranium-exposed Iraqi army.23 Furthermore, p53 overexpression was associated with return of non-muscle invasive bladder cancer (NMIBC) in BCG-treated patient, 24 and this marker could be used as prognostic factor. 25

Recently, there are limited study investigate the role of cigarette smoking exposure toward bladder malignancy process, particularly via p53 and chronic inflammation. Therefore, this research was aimed to investigate the effect of cigarette smoke exposure on chronic inflammatory state and p53 expression in bladder epithelial cells of Wistar rats.

\section{MATERIALS AND METHODS}




\section{Effect of Smoke Exposure on Chronic Inflammation and P53 Expression in Bladder Epithelial}

\section{A. Study Design and Animal Treatment}

This design study was true laboratory experimental post-test only controlled group. As many as 25 male rats (aged 6-8 weeks with weighed 200-250 grams) were obtained from Laboratory of Pharmacology, Faculty of Medicine, Brawijaya University. All rats then randomly assigned into five treatment group as follows: (A) Control Group (without cigarette smoke exposure), (B) Cigarette Smoke 1x [CS-1], (C) CS-2, (D) CS-4, and (E) CS-8 (treated with cigarette smoke 1x/day, 2x/day, 4x/day, and 8x/day, respectively). Cigarette smoke exposure was done in special chamber connected with smoking pump for 15 minutes/ treatment. Cigarette using in this study was obtained from local store (Surya brand, consist of $31 \mathrm{mg}$ tar and 2.2 nicotine/ cigarette).

During study, rats were observed for any distress, behavioral changes, and disease. Body weight was measured before treatment, after 30 days treatment, and at the end of study. After 60 days treatment, all rats euthanized by using ketamine injection intraperitoneally and the bladder was removed for further analysis. All of procedure performed was been approved by ethical clearance in Medical and Health Research with number 400/123/K.3/302/2019.

\section{B. Histology Feature and Chronic Inflamation Score}

Removed, divided into two parts, one of them was fixed in $10 \%$ formalin solution. Preparation of histopathological specimen for hematoxylin eosin (HE) staining was conducted as previously described.26 Briefly, the processes including dehydration, embedded in paraffin block, and sectioning at 5 $\mu \mathrm{m}$ thickness.

Hematoxyllin eosin staining was conducted as previously described. Briefly, specimens were deparaffinized by using xylene, continued with rehydration process using ethanol in reducing manner $(95 \%, 90 \%, 80 \%$, and $70 \%$, respectively). After this process, specimens were stained using hematoxyllin and eosin sequentially. At the final step, specimens were dehydrated by using ethanol and cleared with xylene. The preparation of histopathological specimens was conducted in the Laboratory of Pathology Anatomy, Faculty of Medicine, Brawijaya University.

All slides were observed under light microscope (Olympus BX-51) using 400x magnification. Each specimen were observed for 10 random hpf and analyzed for neutrophil count, lymphocyte count, histiocyte count, presence of edema, congestion, granulation, fibrosis, mucosal erosion, etc. Chronic inflammation score was analyzed as previously described in the literature.27 Briefly, each specimen was observed for neutrophil infiltration, edema, congestion, MMN, granulation tissue, and fibrosis. Furthermore, each HE specimen also observed for any dysplasia and sign of cell proliferation.

\section{Measurement of P53 Expression}

Firstly, half part of bladder organ was fixed in the $10 \%$ buffered formalin. After fixation process, the bladder was embedded in paraffin block, sectioned at $5 \mu \mathrm{m}$ thickness by using microtome and put on the polysine adhesion slides. Paraffin-embedded were stained by using immunohistochemistry method.28 Briefly, following deparaffinization using xylene and rehydration using ethanol, specimens were soaked in peroxidase blocking solution and then incubated with prediluted blocking serum. After blocking process, slides were soaked in primary p53 antibody (p53 mouse monoclonal antibody, Santa Cruz Biotechnology, sc-47698, dilution factor 1:250) at room temperature (10 minutes). Slides then washed with PBS and incubated with secondary antibody at room temperature (5 minutes). Slides then washed with PBS and incubated at room temperature (10 minutes). Slides then washed again with PBS and incubated with DAB (diaminobenzidine) chromogen at room temperature (10 minutes). Slides was be mounting by hematoxylin eosin staining. Expression of p53 was defined as brownish appearance in the nucleus of epithelial and stromal cells.

\section{Analysis Data}

For calculation of chronic inflammation score, neutrophil count, lymphocyte count, and histiocyte count were transformed into ordinal data (originally presented as numeric data). Data analysis was conducted by using software SPSS version 24.0 at confidence interval $95 \%$. Graphical data were made by using GraphPad Prism version

\section{RESULTS AND DISCUSSION}

\section{A. Baseline Characteristic}

Of 25 rats, 20 rats were exposed to cigarette smoke at different frequency $(1,2,4$, and 8 times/ day). During 2 months exposure period, there were no significant difference of body weight among five group at each time point (before treatment, after first month, and after two month). Based on behavioral pattern, there were a decreased food intake and activity especially in highest cigarette smoke exposure group. Furthermore, there were a brownish discoloration on rat's fur particularly in the 4- and 8-times exposure/ day. The mean of body weight of each group during research period were reported in Table 1.

Table-I. Body Weight Before Study, At First Month, And Second Month

\begin{tabular}{cccc}
\hline Group & BW-0 $^{(\text {gram})}{ }^{\mathbf{a}}$ & BW-1 (gram) $^{\mathbf{b}}$ & BW-2 $^{(\text {gram})}$ \\
\hline Control & $229 \pm 2.55$ & $280.4 \pm 5.86$ & $337.4 \pm 5.23$ \\
CS-1 & $230 \pm 7.04$ & $281.4 \pm 7.60$ & $334.6 \pm 10.38$ \\
CS-2 & $232 \pm 3.39$ & $282.6 \pm 3.36$ & $334.6 \pm 2.88$ \\
CS-4 & $232 \pm 2.00$ & $280 \pm 3.08$ & $329.2 \pm 3.63$ \\
CS-8 & $229.8 \pm 1.92$ & $278.2 \pm 3.11$ & $325.6 \pm 3.98$ \\
\hline
\end{tabular}

${ }^{\mathrm{a}}$ : measurement body weight in zero mount or before treatment; ${ }^{\mathrm{b}}:$ measurement body weight first mount or first month after treatment; ${ }^{\mathrm{c}}$ : measurement body weight at second month or second mount after treatment. All data were presented as mean $\pm \mathrm{SD}$.

\section{B. Comparison of Acute and Chronic Inflammatory Level}

Several indicators were used as acute inflammatory state in this study such as neutrophil count, presence of edema, congestion, and mucosal erosion. Our finding showed that there was a significant difference among groups only in neutrophil count (Kruskal-Wallis test, $\mathrm{p}=0.000$ ). Multiple comparison study demonstrated that neutrophil count was significantly higher in control group compared with CS-4 and CS-8 group ( $\mathrm{p}=0.03$ and $\mathrm{p}=0.001)$. Moreover, neutrophil count 
in CS-8 also significantly lower compared with CS-1 group $(\mathrm{p}=0.023)$. Detailed data regarding neutrophil count in each group was represented in Table 2 and Figure 1.

Based on chronic inflammatory indicators, this study showed that there were a significant difference of lymphocyte and histiocyte count among groups $(\mathrm{p}=0.000$ and $\mathrm{p}=0.000$, respectively). However, our study did not find any fibrosis in all groups. Multiple comparison that the lymphocyte count was significantly lower in control group compared with CS-4 and CS-8 $(p=0.041$ and $p=0.001$, respectively). Moreover, the lymphocyte count in CS-8 also significantly higher compared with CS-1 ( $\mathrm{p}=0.003)$. Based on histiocyte count, the number of histiocyte was significantly higher in CS-8 compared with control $(\mathrm{p}=0.003)$ and CS-1 group $(\mathrm{p}=$ $0.001)$. Furthermore, the histiocyte count was significantly higher in CS-4 compared with CS-1 ( $\mathrm{p}=0.032)$. Detailed data regarding neutrophil count in each group was represented in Table 2 and Figure 2 and 3.

Chronic inflammation score was obtained from several parameters including neutrophil count, mononuclear cells infiltration, edema, congestion, granulation, and fibrosis. The result of calculation was presented in Table 2. Our finding on chronic inflammation score was consistent with previous data (lymphocyte and histiocyte count). Multiple comparison study revealed that the chronic inflammation score in the most frequent cigarette smoke-treated group $(\mathrm{CS}-8)$ was significantly higher than control $(\mathrm{p}=0.001)$ and CS-1 ( $\mathrm{p}=0.003)$.

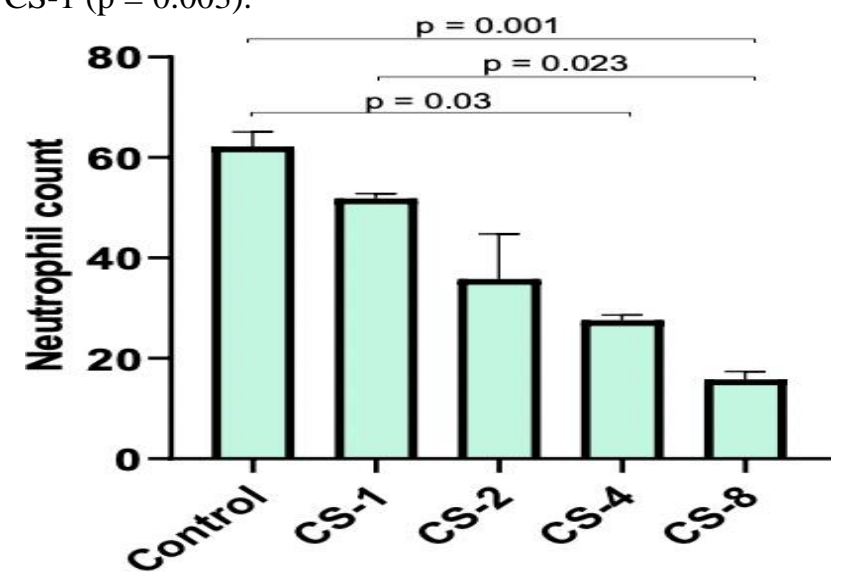

Fig. 1. Neutrophil count in each group

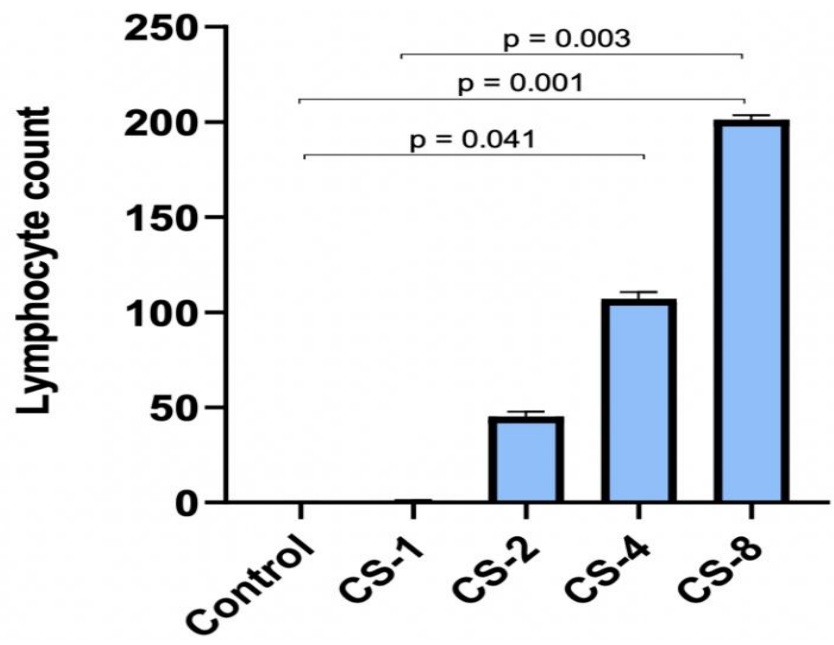

Fig. 3. Histiocyte count in each group

\section{Comparison of p53 Expression}

Immunohistochemistry staining was performed to semi-quantitatively measure the p53 expression in each group. Interestingly, our finding demonstrated that there were no p53 expression detected in control, CS-1, CS-2, and CS-4 group. Expression of p53 was detected in CS-8 group (2 of 5 subjects showed positive for p53 expression, as many as 20 cells from $10 \mathrm{hpf}$ ) (Kruskal Wallis test, $\mathrm{p}=0.011$ ). Further multiple comparison showed significant differences between CS-8 and another group $(\mathrm{p}=0.042)$. Figure 5 represented the features of immunohistochemistry staining for $\mathrm{p} 53$ in bladder.

\begin{tabular}{|l|l|l|l|l|l|l|}
\hline Variables & Control & CS-1 & CS-2 & CS-4 & CS-8 & $\begin{array}{l}\text { P- } \\
\text { value }\end{array}$ \\
\hline Neutrophil count & $62.2 \pm 2.89$ & $51.8 \pm 1.02$ & $35.8 \pm 8.99$ & $27.6 \pm 1.03$ & $15.8 \pm 1.59$ & 0.000 \\
\hline Lymphocyte count & $0.2 \pm 0.20$ & $0.8 \pm 0.49$ & $45.2 \pm 2.63$ & $107.0 \pm 3.67$ & $201.2 \pm 2.39$ & 0.000 \\
\hline Histiocyte count & $0.4 \pm 0.25$ & 0 & $48.2 \pm 2.107$ & $103.4 \pm 3.74$ & $196.4 \pm 2.71$ & 0.000 \\
\hline $\begin{array}{l}\text { Chronic Inflammatory } \\
\text { Score }\end{array}$ & -3.2 & -3 & -2.2 & -0.2 & 1.8 & 0.000 \\
\hline
\end{tabular}




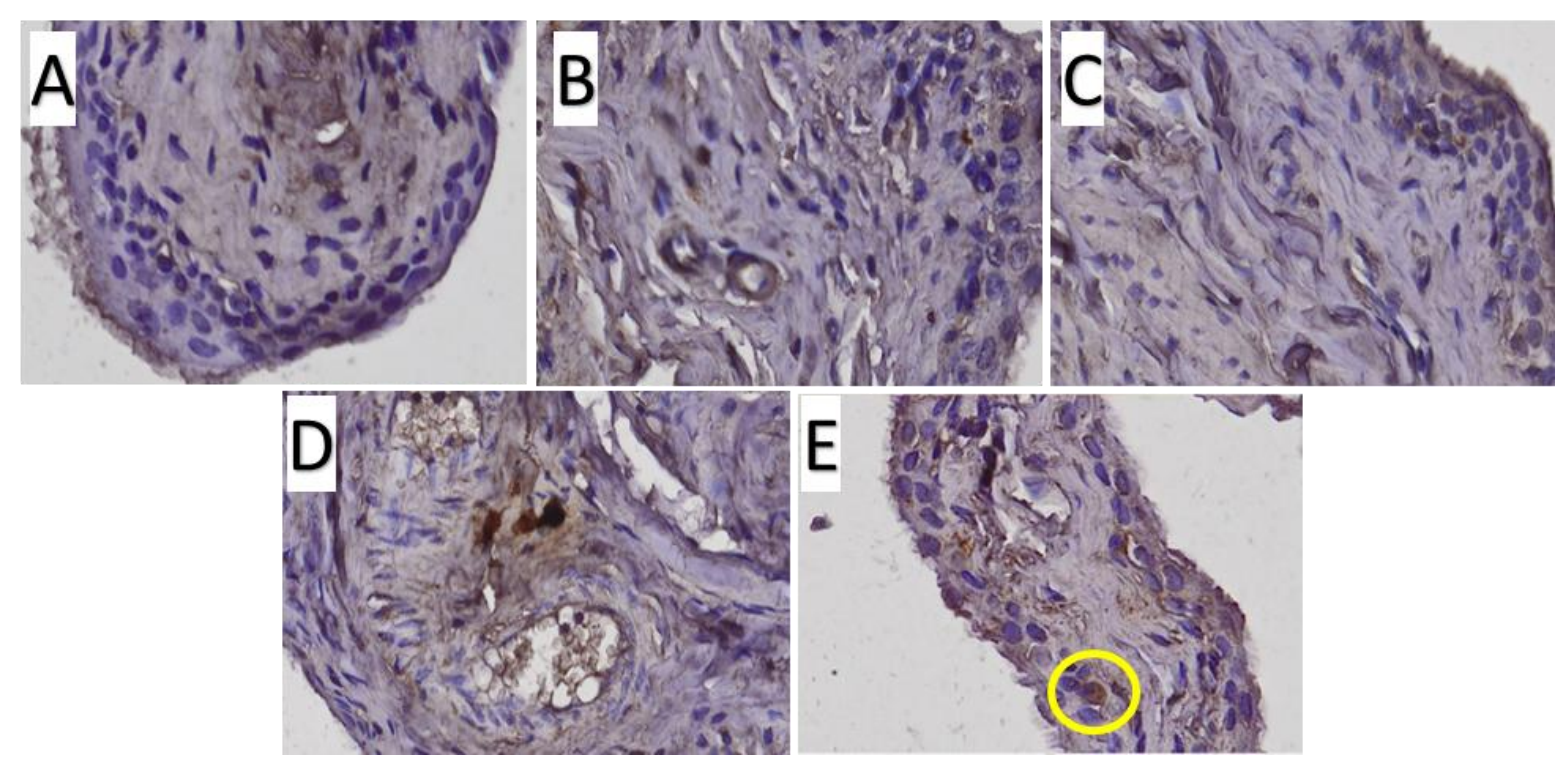

Fig. 4. Immunohistochemistry staining was conducted to detect p53 expression in each group. Picture was obtained by using Olympus BX-51 microscope (400x magnification). (A) Control, (B) CS-1, (C) CS-2, (D), CS-4, and (E) CS-8. Positive p53 was detected in CS-8 group, indicated by yellow circle (epithelial or stromal cells with brownish nuclear staining).

\section{Correlation of Cigarette Smoke Exposure Frequency with Inflammation, Dysplasia, and p53 Expression}

Our data suggested that the frequency of cigarette smoke exposure was negatively correlated with neutrophil count (Spearman correlation test, $\mathrm{p}=0.000 ; \mathrm{r}=-0.918$ ). In the other hand, the frequency of cigarette smoke exposure was positively correlated with mucosal erosion (Spearman test, $\mathrm{p}=0.003 ; \mathrm{r}=$ 0.570 ), lymphocyte count (Spearman test, $p=0.000 ; r=0.956$ ), histiocyte count (Spearman test, $\mathrm{p}=0.000 ; \mathrm{r}=0.928$ ), chronic inflammation score (Spearman test, $\mathrm{p}=0.000 ; \mathrm{r}=0.928$ ), cell proliferation (Spearman test, $\mathrm{p}=0.000 ; \mathrm{r}=0.707$ ), dysplasia (Spearman test, $\mathrm{p}=0.017 ; \mathrm{r}=0.471$ ), and $\mathrm{p} 53$ expression (Spearman test, $\mathrm{p}=0.007 ; \mathrm{r}=0.522$ ). Overall correlation data suggested that higher cigarette smoke exposure increase chronic inflammatory state, trigger dysplasia and proliferation and it is partially mediated by p53 expression.

\section{DISCUSSION}

\section{A. Correlation of Cigarette Smoke Exposure and Chronic Inflammation}

This study showed that frequency of cigarette smoke exposure was strongly correlated with increased chronic inflammatory state and decreased acute inflammatory state. These finding was also supported with enhanced mononuclear cells infiltration (lymphocytes and histiocytes) and reduced neutrophil recruitment.

Cigarette smoke is well known for its nicotine and other toxic constituents which could induce the development of reactive oxygen species (ROS) and further cause dysfunction of mitochondria. ${ }^{29}$ Previous study reported that smoking could increase chronic inflammatory state characterized by increased signal of nuclear factor kappa $b(\mathrm{NF}-\mathrm{kB})$ in lung tissue. ${ }^{30}$ Activation of NF-kB induces transcriptional activity of cytokine proinflammatory, otherwise suppresses transcriptional activity of anti-inflammatory cytokines.

Basically, chronic inflammation is unresolved acute inflammation characterized by fibrosis and continuous mononuclear infiltration and all consequences beyond these processes including damaged and remodeling of tissue. The process is complex interaction between hyper-activation state of immune cells and altered function of residing cells (epithelial and connective tissue cells). ${ }^{31,32}$

Observational study in chronic obstructive pulmonary patients with positive smoking history showed the evidence of mononuclear cells migration (lymphocytes and monocytes), particularly CD8+, into lung tissue and possibly caused by chemokines CXCR3 and CCL5. ${ }^{33}$ This finding was consistent with our finding in bladder tissue. Lymphocytes and monocytes have been studied as a predictor for determining prognosis of patient with urothelial carcinoma. Evidence showed that ratio lymphocyte with neutrophil, lymphocyte with platelet ratio, and monocyte with lymphocyte ration was significantly related with progression and disease-free survival. $^{34}$ Effect of smoking on the destruction of bladder tissue has been studied in human, in vivo, or in vitro. Study using primary culture of human urothelial cells (HUC) reported that cigarette smoke exposure induced uroepithelial damage through increased interaction of platelet activating factor (PAF) with its receptor $^{35}$ and knock out model confirmed the role of PAF. ${ }^{36}$

NLR at 3 month after surgery was strongly correlated with RFS, CSS, and OS in patient with invasive bladder cancer. ${ }^{37}$

At certain point, chronic inflammatory state, which is characterized partially by continuous activation of macrophage, is a risk factor for the malignant transformation. Tumor-associated macrophages (TAMs) has dual effect related to the development of bladder cancer depend on cell polarization (M1 and M2 stage). ${ }^{38}$ M1 stage has cytokine and 
lipopolysaccharide. It could be induced by interleukin (IL)-1 $\beta$, IL-23, IL-6 tumor necrosis factor (TNF)- $\alpha$, interferon- $\gamma$ (IF- $\gamma), \quad$ lipopolysaccharide (LPS), and progression of bladder cancer or showed inhibitory effect on initiation. $^{17,18}$ Otherwise, M2 is activated mainly by transforming growth factor- $\beta$ (TGF- $\beta$ ) or IL-4, IL-10, IL-13 and correlated with induction of proliferation, invasion, migration, metastasis of cell, and suppression of anti-tumor responses. $^{39,40}$ Induction of M1 activity using streptococcus-derived substance confirmed the anti-cancer activity of M1 on bladder cancer. ${ }^{41}$ The other hand, predominant $\mathrm{Mw}$ phenotype in stromal region of bladder cancer was associated with failure of immunotherapy with BCG (Bacillus Calmette-Guerin). ${ }^{40}$ However, the role TAM especially for immune-driven cancer progression still need to be further elucidated. ${ }^{32}$

The role of chronic inflammatory caused by diet or infection on the development of bladder cancer. Cross sectional study involving 690 patients with bladder cancer reported that chronic pro-inflammatory diet (high carbohydrate and lipid) had higher risk of bladder cancer compared than anti-inflammatory diet (high intake of vegetables, fruit, and antioxidants) (OR 1.97; 95\% CI; $\mathrm{p}=$ 0.003). ${ }^{42}$ Chronic inflammation induced by Schistosomiasis infection was also correlated with increased risk for bladder cancer. $^{43}$

\section{B. Correlation of Cigarette Smoke Exposure, Dysplasia, and p53 Expression}

Our data revealed that chronic exposure of cigarette smoke was correlated with cell dysplasia. Furthermore, p53 expression was elevated significantly in the highest cigarette smoke exposure. Protein p53 is well-known as tumor suppressor encoded by p53 gene. P53 is a transcriptional factor which has essential role in regulating the cell cycle and commonly found as mutated form in several malignancy cases, particularly in lethal muscle invasive bladder cancer (MI-BC). ${ }^{44}$

Previous study confirmed three primary genetic alterations which were consistently affect pathogenesis of papillary precursor lesion and non-muscle invasive bladder cancer (NMI-BC) including tyrosine kinase receptor fibroblast growth factor receptor 3 (FGFR-3), phosphatidylinositol-4, 5-bisphosphate 3-kinase, catalytic subunit $\alpha$ (PIK3CA) and Harvey rat sarcoma viral oncogene homolog (H-RAS). ${ }^{45,46}$ In the other hand, alteration in tumor suppressor genes such as p16, Rb99 TP53 was oncogenesis machinery for the development of precursor neoplastic of muscle invasive bladder cancer (MI-BC) termed as CIS and urothelial dysplasia. Evidence also showed that the progression from papillary NMI-BC into high grade MI-BC was depend on TP53 and Rb activation. ${ }^{47}$ Interestingly, observational study reported that p53 was highly expressed in high grade urothelial carcinoma, thus p53 could be assigned as prognostic marker for bladder cancer. ${ }^{48}$

\section{CONCLUSION}

We concluded that there was a significant difference in

chronic inflammation state (lymphocyte and histiocyte count), dysplasia, and p53 expression among groups. Correlation study showed that frequency of cigarette smoking exposure was positively correlated with chronic inflammation, dysplasia, and p53 expression.

\section{ACKNOWLEDGMENT}

We thank Mochammad Abuhari, Lasmijan and Heni Triwahyuni for direct technical assistance during the study.

\section{REFERENCES}

1. Wong MCS, Fung FDH, leung C, Cheung WWL, Goggins WB, Ng CF The global epidemiology of bladder cancer: a jointpoint regression analysis of its incidence and mortality trends and projection.Sci Rep. 2018;8:1129.

2. Steinberg GD, Sachdeva K, Jana BRP. Bladder Cancer. Accessed from http://www.emedicine.com at 1 Agustus 2018.

3. Cancer Facts \& Figures 2018. American Cancer Society. Available at https://www.cancer.org/content/dam/cancer-org/research/cancer-facts-and -statistics/annual-cancer-facts-and-figures/2018/cancer-facts-and-figures2018.pdf. Accessed: August 16, 2018.Cancer Stat Facts, 2018

4. Manley KV, Hubbard R, Swallow D, Finch W, Wood SJ, Biers SM. Risk factors for development of primary bladder squamous cell carcinoma. Ann R Coll Surg Engl. 2017;99(2):155-160.

5. Martin JW, Carballido EM, Ahmed A, Farhan B, Dutta R, Smith C, Youssef RF. Squamous cell carcinoma of the urinary bladder: systematic review of clinical characteristics and therapeutic approaches. Arab J Urol. 2016;14(3):183-191.

6. Ferlay J, Shin HR, Bray F, Forman D, Mathers C, Parkin DM. Estimates of worldwide burden of cancer in 2008: GLOBOCAN 2008. Int J Cancer. 2010;127(12):2893-917.

7. Freedman ND, Silverman DT, Hollenbeck AR, Schatzkin A, Abnet CC. Association between smoking and risk of bladder cancer among men and women. JAMA. 2011;306(7):737-45.

8. Masaoka H, Matsuo K, Ito H, Wakai K, Nagata C, Nakayama T, et al. Cigarette smoking and bladder cancer risk: an evaluation based on a systematic review of epidemiologic evidence in the Japanese population. Japan J Clin Oncol 2016;46(3):273-283.

9. Barbosa ALA, Vermeulen SH, Aben KK, Grotenhuis AJ, Vrieling A, Kiemeney LA. Smoking intensity and bladder cancer aggressiveness at diagnosis. PLoSONE 2018;13(3):e0194039.

10. Burger M, Catto JWF, Dalbagni G, Grossman B, Herr H, Karakiewicz P, et al. Epidemiology and risk factors of urothelial bladder cancer. European Urology 2013;63:234-241.

11. Chuang JJ, Dai YC, Lin YL, Chen YY, Lin WH, Chan HL, et al. Downregulation of glutathione S-transferase M1 protein in N-butyl-N-(4-hydroxybutyl) nitrosamine-induced mouse bladder carcinogenesis. Toxicol Appl Pharmacol 2014;279: 322-30.

12. Van Osch FHM, Jochems SHJ, van Schooten FJ, Bryan RT, Zeegers MP Significant role of lifetime cigarette smoking in worsening bladder cancer and upper tract urothelial carcinoma prognosis: a meta-analysis. Adult Oncol. 2015;195(4):872-879.

13. Van Osch FHM, Jochems SHJ, van Schooten FJ, Bryan RT, Zeegers MP. Quantified relations between exposure to tobacco smoking and bladder cancer risk: a meta-analysis of 89 observational studies. Int J Epid. 2016;45(3):857-870.

14. Van Osch FHM, Vlaanderen J, Jochems SHJ, Bosetti C, Polesel J, Porru S, et al. Modeling the complex exposure history of smoking in predicting bladder cancer: a pooled analysis of 15 case-control studies. Epid. 2019;30(3):458-465.

15. Tortora M, Corsini S, Nistri A. Nicotinic receptors modulate the onset of reactive oxygen species production and mitochondrial dysfunction evoked by glutamate uptake block in the rat hypoglossal nucleus. Neurosci Letters. 2017;639:43-48.

16. Rani V, Deep G, Singh RK, Palle K, Yadav UCS. Oxidative stress and metabolic disorders: pathogenesis and therapeutic strategies. Life Sci. 2016;148:183-193.

17. Rodriguez D, Silvera R, Carrio R, Nadji M, Caso R, Rodriguez G, Iragavarapu-Charyulu V, Torroella-Kouri M. Tumor microenvironment profoundly modifies functional status of macrophages: peritoneal and tumor-associated macrophages are two very different subpopulations. Cell Immunol. 2013;283:51-60.

18. Svatek RS, Zhao XR, Morales EE, Jha MK, Tseng TY, Hugen CM, Hurez V, Hernandez J, Curiel TJ. Sequential intravesical mitomycin plus Bacillus 


\section{Effect of Smoke Exposure on Chronic Inflammation and P53 Expression in Bladder Epithelial}

Calmette-Guerin for non-muscle-invasive urothelial bladder carcinoma: translational and phase I clinical trial. Clin Cancer Res. 2015;21:303-311.

19. Aubrey BJ, Strasser A, Kelly GL. Tumor-Suppressor Functions of the TP53 Pathway. Cold Spring Harb Perspect Med. 2016;6(5). pii: a026062. doi: 10.1101/cshperspect.a026062.

20. Asiri YA. Probucol attenuates cyclophosphamide induced oxidative apoptosis, p53 and Bax signal expression in rat cardiac tissues. Axidative Medicine and Cellular Longevity 2010;3:308-316.

21. Mosadegh M, Hasanzadeh S, Razi M. Nicotine-induced damages in testicular tissue of rats; evidences for bcl-2, p53 and caspase-3 expression. Iran J Basic Med Sci. 2017;20(2):199-208.

22. Kim PH, Cha EK, Sfakianos JP, Iyer G, Zabor EC, Scott SN, et al. Genomic predictors of survival in patients with high-grade urothelial carcinoma of the bladder. Eur Urol. 2015;67(2):198-201.

23. Al-Kashwan TA, Houshmand M, Al-Janabi A, Melconian AK, Al-Abbasi D, Al-Musawi MN, Rostami M, Yasseen AA. Specific-mutational patterns of p53 gene in transitional cell carcinoma among a group of Iraqi patients exposed to war environmental hazards. BMC Research Notes 2012;5:466.

24. Zhou X, Zhang G, Tian Y.p53 status correlates with the risk of recurrence in non-muscle invasive bladder cancer treated with Bacillus Calmette-Guerin: a meta-analysis. PLoS ONE 2015;10(3):e119476.

25. Nagata M, Muto S, Horie S. Molecular biomarkers in bladder cancer: novel potential indicators of prognosis and treatment outcomes. Dis Markers 2016;2016: Article ID 8205836

26. Rosa Tatun,et al. Gambaran CT scan Thoraks Sesai dengan Junis Sitologi/Histologi pada Pasien Kanker Paru yang Merokok. 2016.

27. Cavalli RC, Tambara Filho R, Gomes Rde P, Veronez DA, Slongo J, Fraga Rd. Analysis of the histology of the scar bladder and biochemical parameters of rats with a solitary kidney undergoing immunosuppression with tacrolimus. Acta Circ Bras. 2014;29(8):508-14.

28. Ye G, et al. Puerarin in inducing apoptosis of bladder cancer cells through inhibiting SIRT1/p53 pathway. Oncol Lett. 2019;17:195-200.

29. Arany I, Grifoni SC, Clark JS, Csongradi E, Maric C, Juncos L. Chronic nicotine exposure exacerbates acute renal ischemic injury. AJP Renal Physiology 2011;301(1):F125-33.

30. Zaynagetdinov R, Sherrill TP, Gleaves LA, Hunt P, Han W, McLoed AG, Saxon JA, Tanjore H, Gulleman PM, Young LR, Blackwell TS. Chronic $\mathrm{NF}-\kappa \mathrm{B}$ activation links COPD and lung cancer through generation of an immunosuppressive microenvironment in the lungs. Oncotarget 2016;7(5):5470-82.

31. Schottenfeld D, Beebe-Dimmer J. Chronic inflammation: a common and important factor in the pathogenesis of neoplasia. Cancer Journal for Clinicians 2008;56(2).

32. Sui X, Lei L, Chen L, Xie T, Li X. Inflammatory microenvironment in the initiation and progression of bladder cancer. Oncotarget 2017;8(54):93279-294.

33. Costa C, Traves SL, Tudhope SJ, Fenwick PS, Belchamber KBR, Russell REK, Barnes PJ, Donnelly LE. Enhanced monocyte migration to CXCR3 and CCR5 chemokines in COPD. European Respiratory Journal 2016;47:1093-1102.

34. Song X, Zhang GM, Ma XC, Luo L, Li B, Chai DY, Sun LJ. Comparison of preoperative neutrophil-lymphocyte, lymphocyte-monocyte, and platelet-lymphocyte ratios in patients with upper urinary tract urothelial carcinoma undergoing radical nephroureterectomy. Onco Targets Ther 2016;9:1399-1407.

35. Kispert SE, Marentette J, Campian EC, Isbell TS, Kuenzel H, McHowart J. Cigarette smoke-induced urothelial cell damage: potential role of platelet-activating factor. Physiological Reports 2017;5(5)

36. Marentette J, Kolar G, McHowart J. Increased susceptibility to bladder inflammation in smokers: targeting the PAF-PAF receptor interaction to manage inflammatory cell recruitment. Physiological Reports 2015;3(12).

37. Albisinni S, Moussa I, Aoun F, Quackels T, Assenmacher G, Peltier A, Roumeguere T. The impact of postoperative inflammatory biomarkers on oncologic outcomes of bladder cancer. Progres en Urologie 2019;19(5):270-281.

38. Biswas SK, Mantovani A. Macrophage plasticity and interaction with lymphocyte subsets: cancer as a paradigm. Nat Immunol. 2010;11:889-896.

39. Maniecki MB, Etzerodt A, Ulhoi BP, Steiniche T, Borre M, Dyrskjot L, Orntoft TF, Moestrup SK, Moller HJ. Tumor-promoting macrophages induce the expression of the macrophage-specific receptor CD163 in malignant cells. Int J Cancer. 2012;131:2320-2331.

40. Lima L, Oliveira D, Tavares A, Amaro T, Cruz R, Oliveira MJ, Ferreira JA, Santos L. The predominance of M2-polarized macrophages in the stroma of low-hypoxic bladder tumors is associated with BCG immunotherapy failure. Urol Oncol. 2014;32:449-457.

41. Tian YF, Tang K, Guan W, Yang T, Xu H, Zhuang QY, Ye ZQ. OK-432 suppresses proliferation and metastasis by tumor associated macrophages in bladder cancer. Asian Pac J Cancer Prev. 2015;16:4537-4542.
42. Shivappa N, Hebert JR, Rosato V, Rossi M, Libra M, Montella M, Serraino D, Vecchia CL. Dietary inflammatory index and risk of bladder cancer in a larger Italian case control study. Urology 2016;100:84-89.

43. Gouveia MJ, Santos J, Brindley PJ, Rinaldi G, Lopes C, Santos LL, da Costa JMC, Vale N. Estrogen-like metabolites and DNA-adducts in urogenital schistosomiasis-associated bladder cancer. Cancer Letters. 2015;359(2):226-232.

44. Netto GJ. Molecular diagnostics in urologic malignancies: a work in progress. Arch Pathol Lab Med. 2011;135:610- 621.

45. Zhao M, He X, Teng X. Understanding the molecular pathogenesis and prognostics of bladder cancer: an overview. Chin J Cancer Res. 2016;28(1):92-98.

46. Wang SC, Huang CC, Shen CH, Lin LC, Zhao PW, Chen SY, et al. Gene Expression and DNA Methylation Status of Glutathione S-Transferase Mu1 and Mu5 in Urothelial Carcinoma. PLoS One 2016;11: e0159102.

47. Voltaggio L, Cimino-Mathews A, Bishop JA, Argani P, Cuda JD, Epstein JI, Hruban RH, et al. Current concepts in the diagnosis and pathobiology of intraepithelial neoplasia: A review by organ system. Cancer Journal fo Clinicians 2016;66(5)

48. Qamar S, Inam QA, Ashrafi S, Khan MS, Khokhar MA, Awan N Prognostic value of $\mathrm{p} 53$ expression intensity in urothelial cancers. Journal of College of Physicians and Surgeons Pakistan 2017;27(4):232-236.

\section{AUTHORS PROFILE}

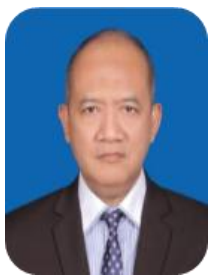

dr. I Gusti Agung Thede Surya Putra Sp. U has completed his urologist degree from Brawijaya University, Malang.

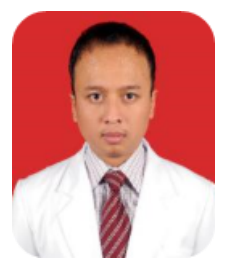

dr. I Gusti Agung Thede Surya Putra Sp. U has completed his urologist degree from Brawijaya University, Malang.

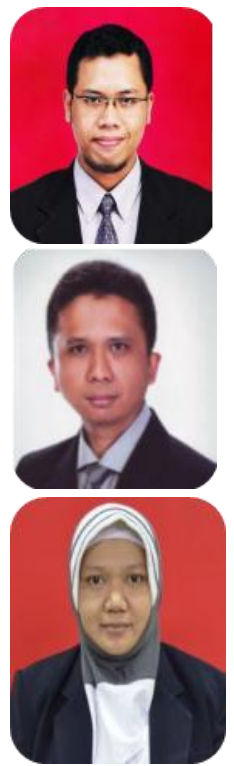

dr. Taufiq Nur Budaya Sp. U has completed his urologist degree from Airlangga University, $\mathrm{He}$ is currently working as urology staff at Urology Department, Brawijaya University, Malang. He has released 2 books about BPH and Malignancy in Urinary Tract.

dr. Kurnia Penta Seputra Sp. U (K) has completed his urologist degree from Airlangga University. He is currently working as urology staff in Urology Department, consultant in Uro-oncology, Brawijaya University, Malang. He has published more than 20 research paper in various national and international journal.

dr. Kenty Wantri Anita Sp. PA has completed his pathology anatomist degree from Diponegoro University. She is currently working as pathology anatomy staff in Pathology Anatomy Department, Brawijaya University, Malang. 